\title{
Hydroacoustic monitoring of a salt cavity: an analysis of precursory events of the collapse
}

\author{
F. Lebert ${ }^{1}$, S. Bernardie ${ }^{1}$, and G. Mainsant ${ }^{1,2}$ \\ ${ }^{1}$ BRGM, Orléans, France \\ ${ }^{2}$ ISTerre, Grenoble, France \\ Received: 15 November 2010 - Revised: 4 July 2011 - Accepted: 28 July 2011 - Published: 29 September 2011
}

\begin{abstract}
One of the main features of "post mining" research relates to available methods for monitoring minedegradation processes that could directly threaten surface infrastructures. In this respect, GISOS, a French scientific interest group, is investigating techniques for monitoring the eventual collapse of underground cavities. One of the methods under investigation was monitoring the stability of a salt cavity through recording microseismic-precursor signals that may indicate the onset of rock failure. The data were recorded in a salt mine in Lorraine (France) when monitoring the controlled collapse of $2000000 \mathrm{~m}^{3}$ of rocks surrounding a cavity at $130 \mathrm{~m}$ depth. The monitoring in the $30 \mathrm{~Hz}$ to $3 \mathrm{kHz}$ frequency range highlights the occurrence of events with high energy during periods of macroscopic movement, once the layers had ruptured; they appear to be the consequence of the post-rupture rock movements related to the intense deformation of the cavity roof. Moreover the analysis shows the presence of some interesting precursory signals before the cavity collapsed. They occurred a few hours before the failure phases, when the rocks were being weakened and damaged. They originated from the damaging and breaking process, when micro-cracks appear and then coalesce.

From these results we expect that deeper signal analysis and statistical analysis on the complete event time distribution (several millions of files) will allow us to finalize a complete typology of each signal families and their relations with the evolution steps of the cavity over the five years monitoring.
\end{abstract}

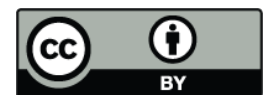

Correspondence to: F. Lebert (f.lebert@brgm.fr)

\section{Introduction}

BRGM (the French Geological Survey), along with INERIS, INPL and MINES ParisTech, is a partner in GISOS (the French Research Group on the Impact and Safety of Underground Works), which is responsible for studying the safety and hazards of abandoned mines. One of the main scientific aims of this group is to determine the mechanisms of cavity collapse using both simulation and observation. In this respect, GISOS is in particular attempting to identify and evaluate the capacity of geophysical (microseismic, hydroacoustic) and geotechnical (extensometer, inclinometer) techniques for monitoring salt cavities' stability.

The experimental site selected for this study is at CervilleBuissoncourt (a few kilometres southeast of Nancy, France) where cavity collapse is the normal consequence of subsurface salt extraction. This site gives GISOS the exceptional opportunity of observing a collapse. In 2004-2005, work began on new extraction facilities and the mine operator kindly agreed to collaborate on the experiment with the GISOS teams. The different organizations involved in GISOS installed an extensive set of sensors to delineate the cavity environment and monitor its behaviour and evolution from the stable state to collapse. The monitoring lasted for five years before the cavity collapse occurred in February 2009.

The objective in this experimental programme was to monitor microseismic activity at field scale in the same way that acoustic emission (AE) are monitored at sample scale, noting that the temporal variation of the AE level (or cumulated level) appears to be related to a variation of temporal stress and strain within the sample. We expected to show how the temporal variation of microseismic activity is related to the variation of temporal stress and strain in the rocks around

Published by Copernicus Publications on behalf of the European Geosciences Union. 
and above the cavity. The aim was neither to characterize each kind of specific event nor to localize their source. We wanted to monitor the collapse as a continuous global event and eventually to focus on recorded features which may precede the collapse.

Here, after a summary dealing with AE research, we describe the main aspects of the salt mine's situation and activity and the technique used for salt extraction. We then analyse the data recorded during the period of collapse, and discuss the processes applied to the data. Finally we consider the interpretation of the signals within a global analysis of the collapse mechanism.

\section{Acoustic Emission (AE)}

\subsection{A few definitions and a short story}

Acoustic Emission (AE) is an elastic wave emission in a solid body resulting from energy released during stress loading. Although the released stress can have different origins, it appears that movement (at microscopic level) is inevitably involved. The most commonly reported mechanism is crack, or micro-crack, formation whereby the AE can be related to destructive events leading to rupture.

AE were first reported around 1936 related to material rupture under stress in the metallurgical research field. They were first mentioned in the Geoscience field by Obert (1941) based on field observations made in 1938. Then came a lot of laboratory experiments that revealed a close relationship between AE and sample strain, particularly at the 'instance of rupture'. Although AE appears to be a constant phenomenon, each experiment showed differences that can be related to the applied technology, the recorded values, the method of stress loading, the nature and quality of the sample (presence of grains, particle size, homogeneity, former cracks, etc.) (Lei et al., 2000; Prikyl et al., 2003). AE monitoring is now currently used in a lot of Geoscience research as a non-destructive method for observing damages in a solid body under stress (up to rupture) (Obert, 1977; Hardy, 2003; Bakhshaiesh, 2009), as well as in a lot of other scientific or industrial activities related to stability and mechanical processes, such as electronics, metallurgy, concrete and building, and electricity (Dalmas et al., 2001; Toubal et al., 2006; Geng, 2006; Shaira, 2006; Richeton, 2006; Sagaidak and Elizarov, 2007; Berbaoui et al., 2009; Kuo, 2009).

It may be easier to consider $\mathrm{AE}$ as a set of Acoustic events (Aev), which are elementary mechanical waves, induced by strain and emitted during mechanical stress on a solid body.

As technology became more refined, it became possible to take into account the evolution of the AE parameter with respect to time or stress variations, in measuring parameters such as activity (cumulated number of Aev, or equivalent time rate), Aev temporal shape, characteristic frequency values (main frequency, spectrum, etc.; Ding et al., 2004; Kui et al., 2007), Aev amplitude, Aev duration, a characteristic time value (upset, decrease, etc.(Majeed and Murthy, 2001; de Ronde et al., 2007), Aev energy and cumulate energy, and the location of Aev sources within the samples. Some people introduced a statistical approach and used the properties of the AE set b-value (relation between Aev magnitude and number; Michihiro et al., 1997; Lei et al., 2000, 2003; Ra and Prasanna Lakshmi, 2005; Lei, 2006; Smith et al., 2009), crack coalescence (evolution of the Aev source location related to time or stress rate). These formalisms use simple (statistical) to highly complex (fractal, etc.) approaches (Kuksenko et al., 1987; Baddari and Frolov, 1997; Lei et al., 2003; Moura et al., 2005, 2006; Lei, 2006; Vilhelm et al., 2008).

Several authors propose relationships between the shape of the Aev and the type of damage or strain and its location (To and Glasera, 2005; de Ronde et al., 2007). In this way, the Aev can be related to a rupture or strain mechanism at microscopic level: grain rupture, cement rupture, cement unstitching from the grain, pore or cavity collapse, cover rupture, cover scaling, grain sliding, fracture sliding, and so on.

Once various results showed that $\mathrm{AE}$ can be used to monitor the rupture process, AE changed from being a purely research subject to being a research tool. Various studies have been performed with measuring AE in laboratory (Lockner, 1993) as a part of their standard monitoring technology set (along with stress, strain, sound velocity, and resistivity). Many scientists involved in seismic-hazard research now use $\mathrm{AE}$ as a seismicity simulation model (Baddari and Frolov, 1997; Lei, 2003; Lei et al., 2003) and work on the sample shape (former cracks, heterogeneous block contact, contact surface shape, etc.). Some researchers use AE to monitor strain when no rupture happens, such as monitoring porosity decrease (Fortin et al., 2009). Moreover, AE monitoring is becoming more and more used in determining precursory patterns to failure at local scale. In particular, it is used in structural damage diagnosis of buildings (Carpinteri et al., 2007), in rockburst mines analysis (Armstrong, 1969; Reymond, 1975; Senfaute et al., 1997; Srinivasan et al., 1999; Lai et al., 2009), and in ground instabilities, such as rocky cliff instabilities (Willenberg et al., 2002; Kolesnikov et al., 2003; Amitrano et al., 2005; Senfaute et al., 2005, Senfaute et al., 2009, Amitrano et al., 2010; Gaffet et al., 2010; Got et al., 2010; Helmstetter and Garambois, 2010), and mudslides (Chichibu et al., 1989; Dixon et al., 1996, 2003; Amitrano et al. , 2007).

\subsection{Relationships between Acoustic Emission (AE) and damages}

Several authors, on the basis of sample studies, agree in describing the evolution to the rupture of a solid body under stress as a step process (Linder et al., 1990; Lavrov and Shkuratnik, 2005; Lei, 2006), i.e.: 


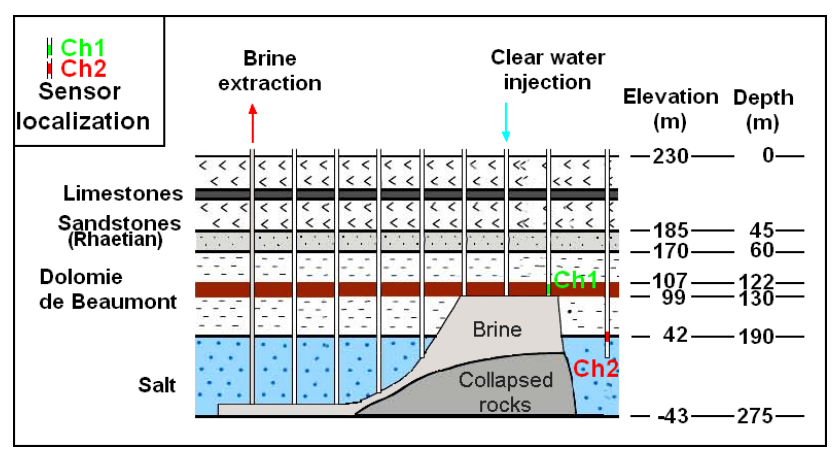

Fig. 1. Geological context and state of the cavity prior to collapse.

1. Loading: the solid body reacts uniformly to the stress; the strain is small and reversible and the Aev show little energy or magnitude and a low activity. As the stress increases, the Aev associated with internal movement changes to Aev related to the first damages (microfracturation, scaling, etc.), which nevertheless remain small, uniformly distributed and unrelated.

2. Fracture growth: with further stress increase, the strain and damages also increase to reach a stage where the damages can no longer remain unrelated to one other; the appearance of one leads to the appearance of another. Due to the imperfection of real bodies (anisotropy, lack of homogeneity, earlier defaults, etc.), the damages and associated $\mathrm{AE}$ evolve from a uniform to a localized distribution. This leads to the formation of defined pathways along which the damages and Aev sources concentrate. AE activity and energy also tend to grow exponentially as the strain and damages increase (in terms of number and size) and become localized, and the strain becomes irreversible.

3. Rupture: the damages and localized Aev pathways eventually become rupture pathways. Macroscopic movements occur and fractures appear, sometimes abruptly, whilst the strain rate, damages and AE become explosive. Nevertheless, depending on the stress rate and body size, rupture can be a drawn out process.

\section{Site context, collapse mechanism}

\subsection{Geological context and salt dissolution technology}

The monitored cavity is located on a plateau in the east of France. The salt beds, about $100 \mathrm{~m}$ thick at a depth of $185 \mathrm{~m}$, are overlain by soft layers, mainly clay and marl, with some limestone and sandstone intervals. At a depth of $120 \mathrm{~m}$ within this stack (see Fig. 1) is a very rigid dolomite bed ( $\sim 10 \mathrm{~m}$ thick) known as the "Dolomie de Beaumont" (DdB) which provides stability for the salt cavity due to its high mechanical strength.
The mine operator uses dissolution technology along a straight-line of boreholes connected at their bottom by hydraulic fracturing. The salt is extracted from brine pumped out at one end of the path while clear water is injected at the other (Fig. 1). The injected water dissolves the salt and forms a cavity near the injection borehole. As extraction proceeds, this cavity grows and extends upward into the overlying clay and marl layers. These in turn collapse until the "DdB" layer is reached. Because of this layer's strength, the cavity now can only grow horizontally; this weakens the "DdB" which will eventually collapse along with all the overlying layers once the cavity is large enough.

\subsection{Collapse mechanism}

Considering that the mine operator will extract all the salt, cavity collapse is unavoidable. Nevertheless it can be planned and controlled by regulating the cavity's mechanical stability (or instability) and constraining its stress state. One method is to control the water level within the mine site since this pushes up the roof cavity. Pumping out the brine draws down the water level, thus decreasing the inside pressure. This, in turn, increases the stress within the rocks, but in a complex way with variations depending on the cavity geometry and on former fractures.

The stress variations can be evaluated from the water level monitored by the operator during the controlled collapse operation. Here the water level was about $27 \mathrm{~m}$ deep at the beginning of the operation.

\section{Method and sensors sets}

\subsection{Monitoring-sensor sets}

The use of the hydrophone is very attractive as this sensor is well coupled with the medium. It allows recording the acoustic activity with a high sensitivity over a large range of frequencies. Indeed, the spectrum content of the recorded event depends on the event itself, and on the attenuation of the signal between the source location and the sensor. If we consider a simple source model, the corner frequency $f_{c}$ is linked to the source dimensions following the relationship:

$f_{c}=(\zeta . c) / r_{0}$

where $c$ is the body-wave velocity in the vicinity of the source, $r_{0}$ is the source dimension, and $\zeta$ is a constant that depends on the particular source model.

The smaller the source, the higher the frequency corner is. Furthermore, the amplitude of the signal emitted decreases during the propagation, due to geometrical expansion, as well as the attenuation of the material related to an elastic behaviour of the material. The first term decreases with the inverted squared distance of propagation. The second one depends on the material nature and on its fracturation state. 


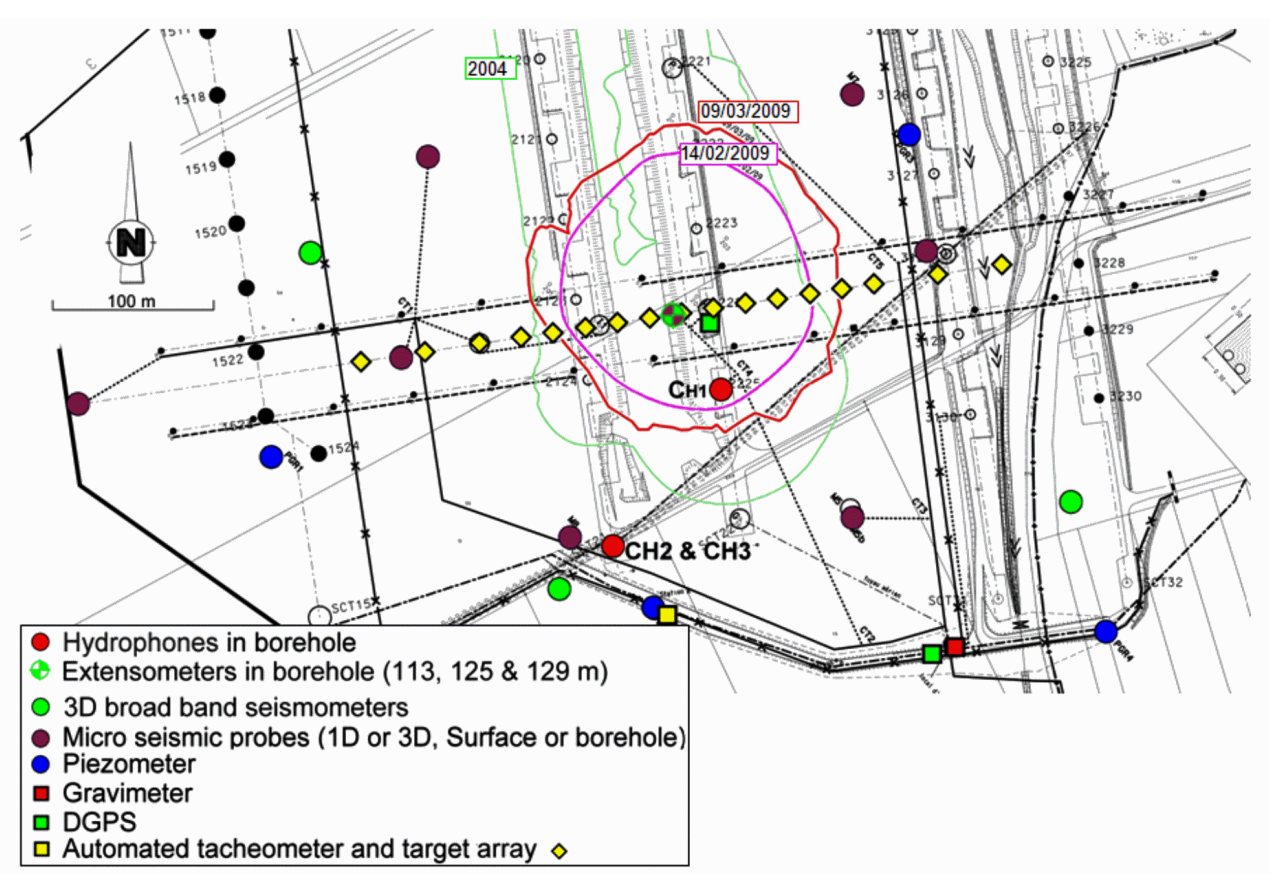

Fig. 2. Location of the hydrophone and sensor network.

The intrinsic attenuation depends on the frequency as it is described in the following equation (Aki and Richards, 1980):

$A(r)=A_{0} \cdot \exp (-\pi \cdot R \cdot f / c \cdot \mathrm{Q})$

Where $r$ is the distance of propagation, $A_{0}$ is the signal amplitude at source, $A(r)$ is the observed signal amplitude at sensor, $f$ is the seismic frequency, $\mathrm{Q}$ is the quality factor. The attenuation is higher for high frequencies.

The frequency bandwidth of the sensor is chosen large, (from $30 \mathrm{~Hz}$ to $180 \mathrm{kHz}$ ) allowing us to record a large range of phenomena size, from centimetres to hectometres.

The design of the hydroacoustic monitoring array is based on the context site (cavity filled with brine, dimension and depth of the cavity), the geology (in particular with the presence of a rigid "DdB" layer) and technical constraints. The location of the hydrophones is chosen in relation to the location of the "DdB" layer and to the subsurface cavity, as determined from the well logging data supplied by the operator (see the green contour of about $150 \mathrm{~m}$ diameter in Fig. 2; the pink contour in this figure marks the edge of the sinkhole immediately after the collapse, and the red contour the edge of the sinkhole three weeks after the collapse).

A complete description of all the sensors from each team is given in Appendix A. The hydroacoustic measurements came from a set of three ITC hydrophones $(180 \mathrm{kHz}$ bandwidth, $-143 \mathrm{~dB}$ sensitivity) installed in two boreholes (red points):
- one hydrophone (Ch1) installed in Borehole S2225 and within the cavity zone at the level of the "DdB" layer $(125 \mathrm{~m})$. This sensor turned out not to be in the centre of the collapse as expected, but very close to the collapse border (pink limit);

- two hydrophones in Borehole SCT 21 outside the cavity zone; hydrophone $2(\mathrm{Ch} 2)$ near the level of the salt roof $(185 \mathrm{~m})$ and hydrophone $3(\mathrm{Ch} 3)$ at the level of the "DdB" layer (125 m).

The Ch1 and Ch2 hydrophones were associated with a set of filters and amplifiers which split the signal into three frequency bands:

- low frequencies from $30 \mathrm{~Hz}$ to $3 \mathrm{kHz}(\mathrm{LF})$,

- medium frequencies from 3 to $30 \mathrm{kHz}$ (MF),

- high frequencies from 30 to $180 \mathrm{kHz}(\mathrm{HF})$,

which recorded the RMS intensity ( $1 \mathrm{~s}$ sample rate), HF events $(4 \mathrm{~ms}$ long, sample rate at $1 \mathrm{MHz})$ and $\mathrm{LF}(0.5 \mathrm{~s}$ long, sample rate at $10 \mathrm{kHz})$. All events ( $\mathrm{HF}$ and $\mathrm{BF})$ were recorded on level triggering. The $\mathrm{Ch} 3$ hydrophone had only a HF bandwidth and therefore only recorded the HF events.

The strain measurements came from a set of three extensometers installed in a same borehole (Fig. 2, crossed circle) to monitor the deformation of the "DdB" layer. They were anchored from the surface to lie above, within and below the dolomite layer and named according to their depth $(113,125$ and $129 \mathrm{~m}$ ). 

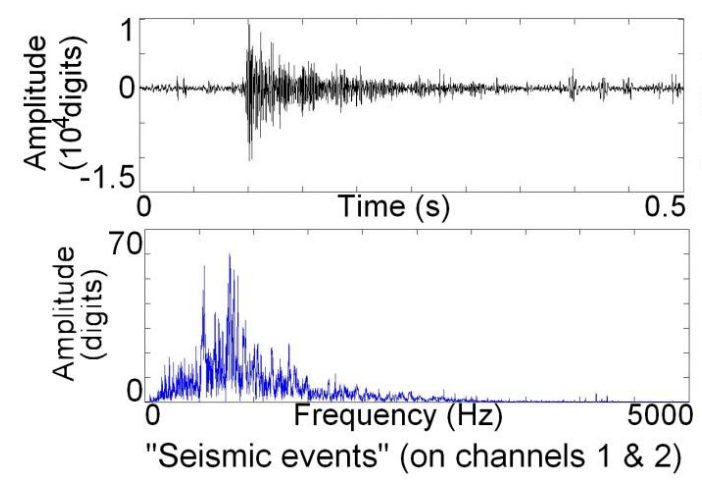

Fig. 3. Examples of characteristic "seismic" and "X" event records.

\subsection{Event definition}

Many microseismic surveys aim at localizing the event source, allowing magnitude computation. For that, it is necessary to get events recorded by a maximum of sensors (minimum: 4 , typically: 6 to 8 ) at the same time, leading to some choices in both recording and results computing. In this study, the objective was not to localize the events. Each $\mathrm{BF}$ recorded file is used as an event: each $\mathrm{BF}$ file is $0.5 \mathrm{~s}$ long with trigger time at $0.1 \mathrm{~s}$. The threshold level is fixed at three times the noise level. The recording system is adapted to record again immediately at the end of the current recorded file. Thus the whole signal is recorded in case the threshold value is attained. In this case, it may lead to redundancy in the first hundred milliseconds of the record. A process is applied to the recorded signal to remove the redundancy.

When events shorter than the file length and with amplitude greater than the threshold happen at a very short time lapse, they may be recorded in a unique file; in this case the number of events is underestimated, but the energy computation and its time localization is correct (at a scale greater than the file time length).

That is why we chose to work on the time energy repartition instead of on the time event repartition.

\subsection{Amplitude and energy computation}

There is a direct link between the amplitude of acoustic pressure $(p)$, acoustic intensity (I) and acoustic power $(\mathrm{P})$ as the acoustic intensity is the power flux across a surface (S):

$\mathrm{I}=p^{2} / \mathrm{Z}=\mathrm{dP} / \mathrm{dS}$

where $\mathrm{Z}$ is the acoustic impedance $(\mathrm{Z}=\mathrm{C} \times \rho$, product of the sound celerity: $\mathbf{C}$, and the bulk density: $\rho$ ). As the power is the temporal variation of energy $(\mathrm{W}): \mathrm{P}=\mathrm{dW} / \mathrm{dt}$, let us introduce the sound displacement $\mathrm{dx}$ in the preceding equation; this leads to:

$\mathrm{I}=p^{2} / Z=(d W \times d x) /(d S \times d t \times d x)$
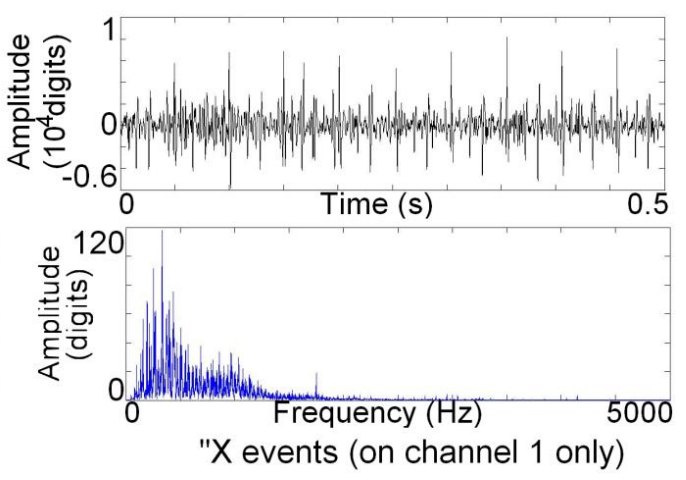

Where $\mathrm{dx} / \mathrm{dt}$ is the sound celerity (C), and $\mathrm{dS} \times \mathrm{dx}=\mathrm{d} V(V$ is the volume); it comes:

$I=p^{2} / Z=d W / d V \times C$

So, for a unitary volume $\left(\mathrm{d} V=1 \mathrm{~m}^{3}\right)$, we may write:

$d W=I / C=p^{2} /(Z * C) ;$ unit is in $\mathrm{Jm}^{-3}$.

We used brine values for computations:

- Bulk density: $\rho=1197 \mathrm{~kg} \mathrm{~m}^{-3}$

- Sound celerity: $\mathrm{C}=1700 \mathrm{~m} \mathrm{~s}^{-1}$

- Acoustic impedance: $Z=2034900$ Pa.s m$^{-1}$

\section{Data analysis}

In this article, we focus our analysis on the low frequency events (from $30 \mathrm{~Hz}$ to $3 \mathrm{kHz}$ ). The results obtained regarding the signals acquired in the high frequency bandwidth are interesting and could be the subject of another paper.

\subsection{Signal typology: "seismic" and " $X$ " signals}

Each hydrophone channel collected a large amount of data during the five years of monitoring. Here we shall focus only on analysing the records from 2008 to 2009 , during which time more than 500000 events were recorded. We tried to find significant descriptions for the different kinds of events so as to be able to divide them into specific subsets; these proved invaluable in our study of the controlled collapse, where we obtained especially good results from the LF event set.

We were able to distinguish two major kinds of signals from the temporal spectral shapes, samples of which are shown in Fig. 3:

- Most of the recorded signals $(\sim 86 \%)$ were variations of a usual seismic signal with a strong beginning and a 


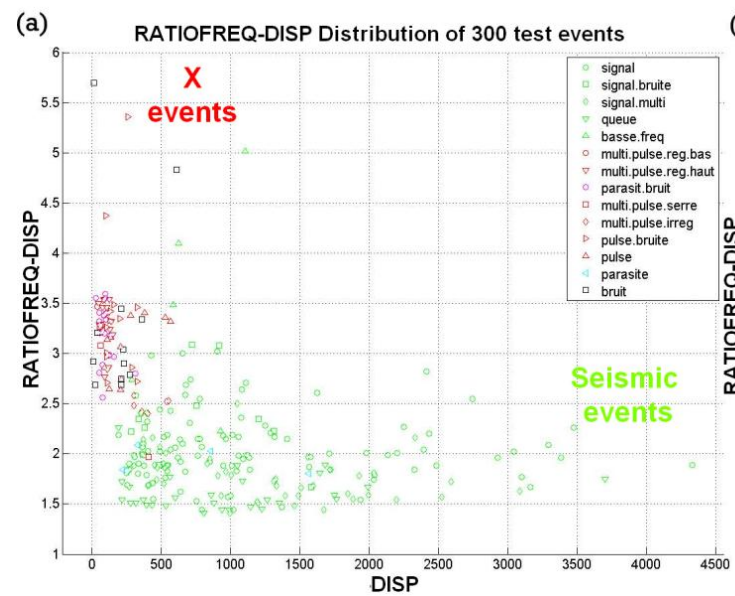

(b) RATIOFREQ-DISP Distribution of 120000 events

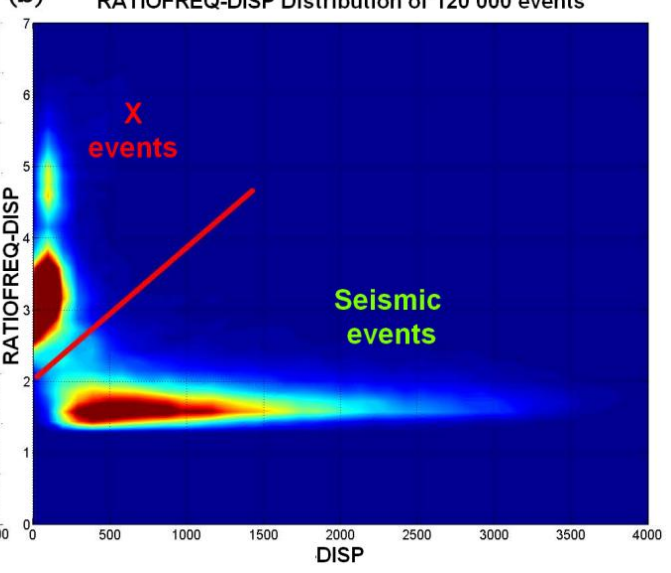

Fig. 4. Separation of "X" and "seismic" event families on a RATIOFREQ versus DISP crossplot (a: samples, b: set of 120000 events).

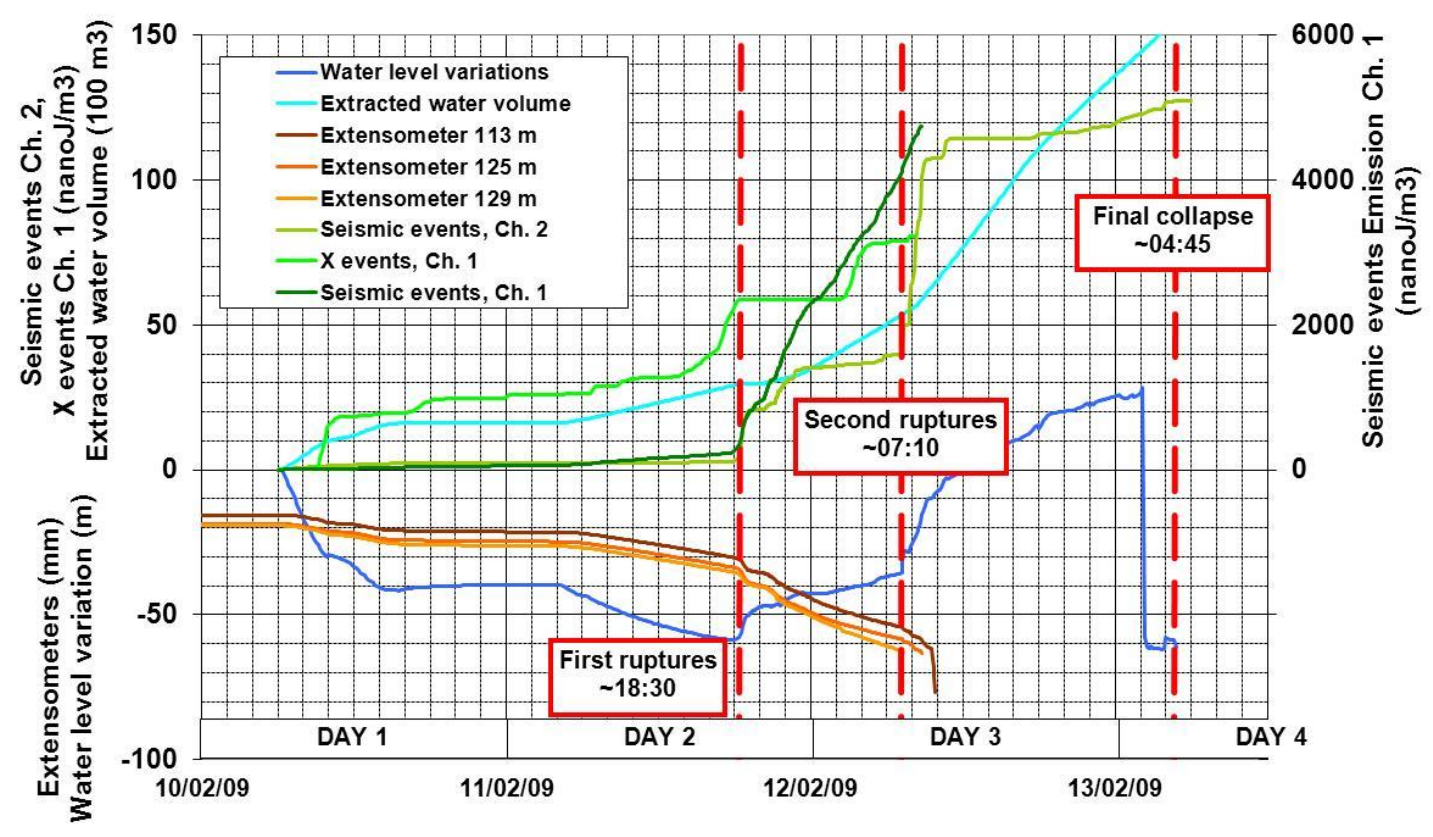

Universal Time

Fig. 5. Evolution of stress, strain and AE energy during the controlled collapse.

smooth decreasing end. This shape shows that the energy distribution inside the time window was not uniform; consequently it presents a high statistical dispersion. The frequency representation shows a broad extension of the spectrum with a good representation of all frequencies, and particularly the higher frequencies, and major lines in the 500 to $1000 \mathrm{~Hz}$ interval. For convenience we have termed these as "seismic" signals.

- The second kind of signal has uncommon characteristics. It shows a uniform distribution of short spiky signals along the time window, indicating a lower overall energy value and a lower statistical dispersion. The frequency representation shows major lines at the lower frequencies (100 to $600 \mathrm{~Hz}$ ) and a less extensive spectrum in the high frequencies. The major lines are more energetic, albeit with an overall energy that is lower than that of the "seismic" signal lines of equivalent temporal maximum amplitude. Some of them show a harmonic distribution of the lines. For convenience, we have termed them " $\mathrm{X}$ " signals and they only occur on $\mathrm{Ch} 1$ (inside the cavity zone). 


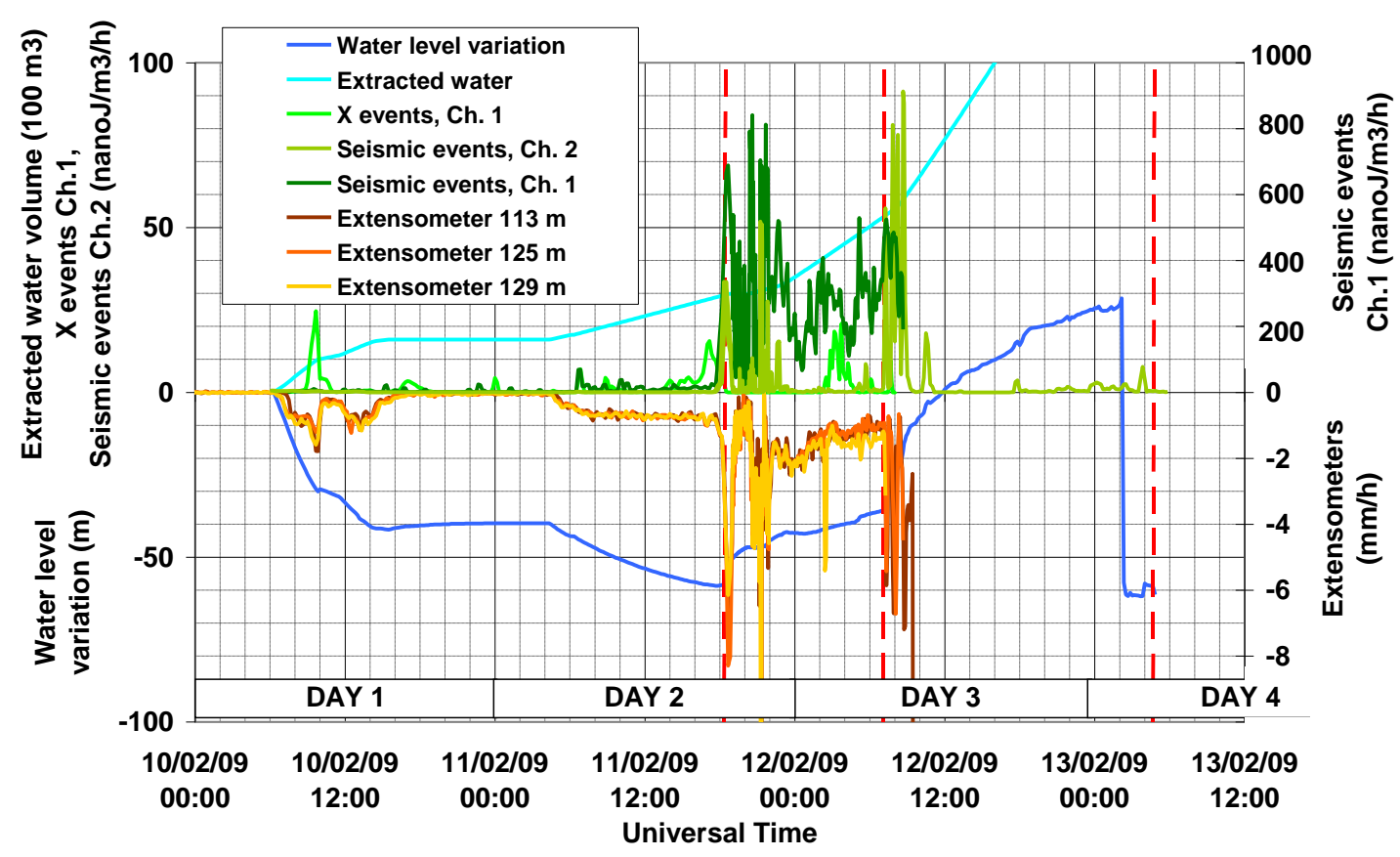

Fig. 6. Evolution of stress, strain rate and AE energy rates during the controlled collapse.

The characteristics of the two signal types enabled us to use simple indicators for distinguishing them:

- The DISP indicator, in the temporal domain, represents the compactness of the energy distribution along the time window. It is the standard deviation of the RMS signal on five consecutive $0.1 \mathrm{~s}$ sub-windows inside the main $0.5 \mathrm{~s}$ window:

$$
\begin{array}{r}
\text { DISP }=\text { Standard }- \text { Dev }\left(\mathrm{RMS}_{0->0.1}, \mathrm{RMS}_{0.1->0.2},\right. \\
\text { RMS } \left._{0.2->0.3}, \mathrm{RMS}_{0.3->0.4}, \mathrm{RMS}_{0.4->0.5}\right)
\end{array}
$$

- The Frequency Ratio indicator represents the relative proportion of low-amplitude frequency lines in the frequency spectrum. It is the number of samples with a value below the spectral mean divided by the number of samples with a value above the spectral mean:

RATIOFREQ $=\frac{\text { Number of spectral lines with a value below the spectral mean }}{\text { Number of spectral lines with a value above the spectral mean }}$

The distribution of event samples in a diagram built with these two indicators shows a good separation of the two families (Fig. 4a), as does the density diagram built using more than 100000 unsorted event files (Fig. 4b). These simple indicators thus enabled us to automatically split the entire LF event set into two subsets: "seismic" events and " $X$ " events.

\subsection{Distribution of the "seismic" and " $X$ " event subsets}

When analysing the behaviour of each signal type, we have to bear in mind the controlled-collapse scenario described from all the data recorded by the GISOS teams (Contrucci et al., 2010; Daupley et al., 2010a, b; Jousset et al., 2010; see Appendix B). The controlled collapse occurred between the 10 and 13 February 2009 and was provoked by pumping the brine. Three main events took place over the four days of the collapse process:

- Layer fracturing around a cylinder of rock in the layers above the cavity, which resulted in the cylinder slipping down on the 2 nd day at $\sim 18: 30^{1}$,

- Rupture of the residual competent dolomite layer on the 3rd day at $\sim 07: 10$, which damaged the sensors located above the cavity and also the cavity,

- A final surface collapse on the 4th day at $\sim 04: 45$.

The evolution of all the measurements over this period are shown on Figs. 5 and 6: i.e. water level, extracted water volume, cumulated energy of the LF event subsets, "seismic" events on the Ch1 hydrophone (Sev.Ch1) and Ch2 hydrophone (Sev.Ch2), " $X$ " events on the Ch1 hydrophone (Xev.Ch1), and strain on the 113, 125 and 129 m extensometers. The two figures respectively show their temporal variation and the temporal variation of their time rates.

During the first part of the controlled collapse (from the start up to the first ruptures), the water-level (dark blue) and extracted water volume (light blue) curves show that pumping began early on the morning of Day 1 and continued until around 16:00. It was stopped during the 1st night and also

\footnotetext{
${ }^{1}$ All times are given in Universal Time (UT)
} 
a few hours after the first ruptures occurred around 18:30 on Day 2. From this moment on, and despite the pumping, the water level kept rising due to subsidence of the rock cylinder.

The strain curves (orange and brown lines) follow the water-level variations up to the first ruptures, at which point they show a steep step.

The Sev.Ch1 curve (dark green) is quiet until the first ruptures, when its level raises almost uniformly until the second rupture damages the Ch1 hydrophone. The Sev.Ch2 curve (medium green) shows a succession of tranquil and active episodes, with particularly strong activity during $\sim 5$ to 6 hours following the first ruptures.

The Xev.Ch1 curve (light green) shows a first main period of growth during Day 1 from 09:00 to 10:00, when the water level decreased by about $30 \mathrm{~m}$ - a level that corresponds to the level reached during pumping tests in 2005 and 2007. The "X" energy then increased stepwise until a dramatic acceleration during Day 2 from about 13:40 to 18:30, before the first ruptures at which point it becams quiescent while other channels showed activity.

During the second period (between the first and second ruptures), the water level rose due to the cylinder subsidence, despite pumping. On Day 3, at $\sim 02: 00$, the extensometer 129 curve separated from the other two, which may indicate that the residual competent "DdB" layer had already begun to rupture at this time.

The Sev.Ch1 curve (dark green) shows a high and uniform increase until the $\mathrm{Ch} 1$ hydrophone is destroyed. At this point, the total cumulated energy is $4800 \mathrm{nanoJ} \mathrm{m}{ }^{-3}$ on the Sev.Ch1 curve.

The Sev.Ch2 curve (medium green) shows high activity for $\sim 2 \mathrm{~h}$ from the second rupture (this being its main period of energy increase). Of note is that the cumulated energy on the Sev.Ch2 curve at the moment of the second rupture is only $\sim 115 \mathrm{nanoJ} \mathrm{m} \mathrm{m}^{-3}$, which is much lower than that on Channel 1.

" $\mathrm{X}$ " activity resumed again early in the morning of Day 3, from $\sim$ 02:00 to 04:00 when the extensometers separated during quiescence in the Sev.Ch2 curve. Note that the strong seismic activity (Sev.Ch1) during this period does not mask the "X" event activity (Xev.Ch1) recorded on the same hydrophone.

At the moment the Ch1 sensor was damaged (i.e. at the second rupture), it can be seen that the cumulated energy on the Xev.Ch1 curve is only $\sim 80$ nanoJ m${ }^{-3}$, which is much less than on the Sev.Ch1 curve.

Taking into account the time rate variations, one sees a good correlation between the extensometer curves and the Sev.Ch2 curve for the three main episodes: the first at the first rupture, the second $\sim 2 \mathrm{~h}$ later and the third $\sim 2 \mathrm{~h}$ before cavity sensors were damaged.

During the third period (from the second rupture to final collapse), the Sev.Ch2 curve (medium green) showed high activity during the third night up to the moment of final collapse.

\section{Discussion}

\section{1 "X" and "Seismic" events' significance}

Both the "X" events and "seismic" events were recorded by the same hydrophone (Ch1), with the split process of event subsets only taking into account the intrinsic signal property of each event record. However, in relation to the collapse, the location of the hydrophones turned out not to be as predicted when they were installed. The Ch1 hydrophone in the "DdB" layer ended up being very close to the collapse margin $(\sim 12 \mathrm{~m})$ rather than at the centre, and the Ch2 hydrophone, near the salt roof level, was farther away than expected $(\sim 95 \mathrm{~m})$. The "seismic" events were recorded in both the $\mathrm{Ch} 1$ and $\mathrm{Ch} 2$ hydrophone event sets. Their respective energies are not of the same order; this could be due to the relative distance from the event sources; it can be assumed that the $\mathrm{Ch} 2$ hydrophone only received signals from the largest events with sufficient energy to travel $\sim 100 \mathrm{~m}$ and more in distance. Conversely, the Ch1 hydrophone appears to be very close to the expected location of the microseismic sources (at the edge of the collapse area).

It is interesting to note that the " $\mathrm{X}$ " events, which were recorded only by the Ch1 hydrophone and not the Ch2 hydrophone event set, always appeared before a period of intense strain, such as:

- when the decrease in water level reached $30 \mathrm{~m}$, which is the value of the water-level drawdown reached during the 2005 and 2007 pumping tests;

- during a period of four hours before the first ruptures at the cavity border, as described by the proposed collapse mechanisms;

- during a period of two to three hours before the rupture within the residual "DdB" layer, as described by the proposed collapse mechanisms.

Both seismic event channels, however, show that extreme activity only occurred during periods of intense strain.

Rock rupture is not an instantaneous process; even for a core sample during a test, it is a complex process as explained in $\S 2.2$. It begins when the stress exceeds the sample resistance and lasts until the macroscopic failure. In this reported in situ experiment, GISOS teams identified several "macroscopic" failures followed by intense strains. The "seismic" events appear to be the consequence of these post-rupture rock movements related to the intense deformation of the cavity roof. But the "X" events occur before these periods of movement. This could mean that the $\mathrm{X}$ events come from the damaging and breaking process, in the same way that $\mathrm{AE}$ comes before sample destruction in a laboratory test, when micro-cracks appear and then coalesce (phase 2 of the breaking process). 


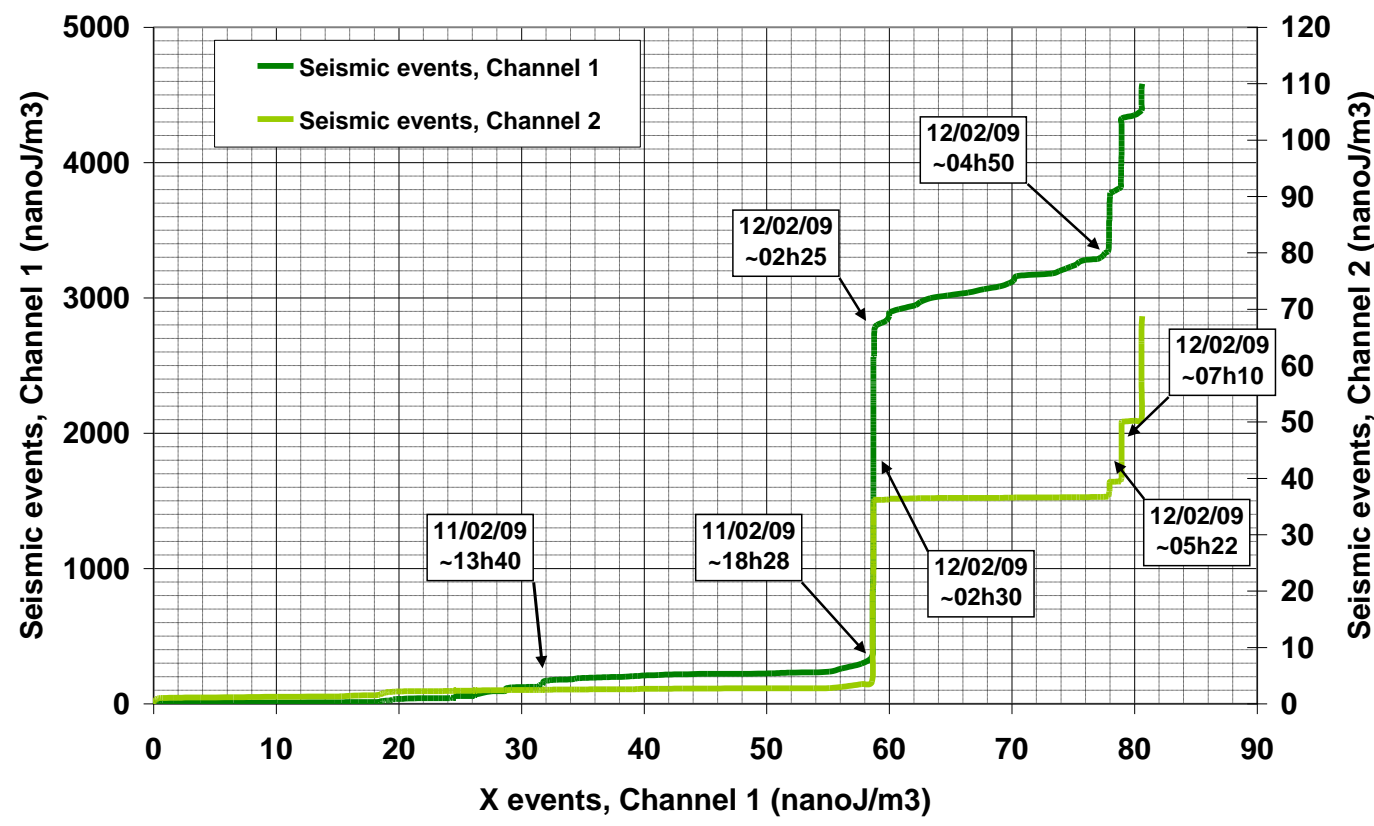

Fig. 7. Evolution of the AE energy during the controlled collapse (parametric representation of "seismic" energy from channels 1 and 2 versus "X" energy from channel 1).

A third way to represent the relationships between the different kinds of events is to plot "seismic" signal energy versus " $\mathrm{X}$ " signal energy (Fig. 7). This emphasises two aspects of what was recorded because it very clearly shows:

- the periods of quiescence and activity for each channel and

- the opposition between the "X" and "seismic" signals i.e. when the "X" events are active, the "seismic" events are quiet, and vice versa.

The so called "seismic" signal may be associated with strain and related movements (e.g. piston slip, block slip) as a consequence of the rupture. Conversely, the " $\mathrm{X}$ " signal is associated with periods of little or no motion, which may represent episodes of stress loading and rock damage (i.e. partial and local breaks). The "X" signals appear before episodes of accelerated subsidence, when the cavity roof rocks are still in place but weakened:

- when subsidence increased on 11 February 2009 at $\sim 18: 30$, the hard layer macroscopically broke at the cavity margin. "X" events were recorded over a period of five hours before this occurred;

- when subsidence dramatically increased on 12 February 2009 at $\sim 07: 00$, the hard layer had already broken away. Again, "X" events were recorded over a period of five hours before motions occurred.
Our field observations back up the phase descriptions reported by other authors on sample experiments, even though relationships between field and laboratory experiments are not straightforward due to the difference in dimensions and complexity. We found a clear difference between the periods before macroscopic rupture (" $\mathrm{X}$ " events probably being related to microscopic rupture) and the periods following macroscopic rupture ("seismic" events probably being related to macroscopic motion).

\section{2 "Kaiser effect"}

The Xev.Ch1 curve shows a first main period of growth at the beginning of the experiment when the water level reached the level reached during former pumping tests in 2005 and 2007 (day 1 from $\sim 09: 00$ to 10:00). This observation suggests a 'Kaiser effect' or at least a memory effect.

The "Kaiser effect" (Kaiser, 1950) was first observed and defined after cyclic loading experiments on metal samples. Then it was used and "extended" to other material fields, especially rocks. The objective was to reach the in-situ stress field (Holcomb, 1993) from laboratory loading experiments (laboratory stress is controlled and less complex than in situ).

Rocks show much more heterogeneities than metal, at grain scale, because of the grain distribution (dimensions, shape, nature ...) and the eventual matrix. That's why the "Kaiser effect" in rocks is not universally admitted. Moreover, the complexity of contact surfaces involved in a real macroscopic geologic system leads us to admit that acoustic emissions due to strains may come from both breakings (at 
any scale) and friction (from motions at any scale, along any surfaces). It is clear that breakings are single shot events and may not happen again before the precedent stress state is exceeded. This seems to be the main explanation of the 'Kaiser effect'. On the contrary, motions may play during loading/unloading and rubbing may be expected in any case.

However that may be, considering the " $\mathrm{X}$ " events as rupture-generated events is in accordance with the interpretation of a "Kaiser effect".

In this context, this observation could be a "Kaiser effect" if we can demonstrate that the former pumping tests and the last one reported here may look as a kind of cyclic load experiment where stresses grew as the system stays unchanged. It is not truly the case, because the rocks under the 'DLB' layer, at the cavity top, fell down in the cavity in several phases independent from the pumping tests. This means that neither the geometry nor the stress field remained stable during the time including the experiments.

\section{Conclusions}

Hydroacoustic monitoring of the controlled collapse of the Cerville-Buissoncourt salt cavity highlighted some interesting precursory signals before the cavity collapsed, with the cumulative energy evolution of the LF events. Particularly the analysis of the LF events led to the identification of two Aev families, here termed " $X$ " events and "seismic" events. The two sets can be distinguished by their different signal energy distributions in both the time and frequency domains.

Time wise, it was noted that the "seismic" events occurred during periods of macroscopic movement, once the layers had ruptured; they appear to be the consequence of the postrupture rock movements related to the intense deformation of the cavity roof; the " $\mathrm{X}$ " events occurred before these episodes when the rocks were being weakened and damaged. They come from the damaging and breaking process, when micro-cracks appear and then coalesce.

As with all preceding reports on this subject, it is clear that there are still aspects that need to be clarified before we can adapt the results to a tool for forecasting collapse. Particularly, we have to finalize a complete typology of each signal family as we expect variations (of shape or amplitude) due to the rock stress or strain variation. This work will involve the complete event time distribution over five years (several millions of files). Thus, with this aim in view, we shall need to perform a more deep signal analysis of each event type and a more deep statistical analysis of their distribution related to the known partial collapse events.

\section{Appendix A}

\section{Instrument layout}

Each GISOS team installed their own sensor sets according to the cavity margin determined from sonar well logging performed by the operator. The locations of these sensors are shown on Fig. 2, as is the cavity margin (green contour of about $150 \mathrm{~m}$ diameter).

- BRGM: 3 hydrophones ( $30 \mathrm{~Hz}$ to $3 \mathrm{kHz}, 3$ to $30 \mathrm{kHz}$, and 30 to $180 \mathrm{kHz}$ frequency bands) in two drill holes (red points),

- INERIS: 11 down-hole and near-surface microseismic 1 -D and 3-D probes (40 to $1000 \mathrm{~Hz}$ frequency band, $8 \mathrm{kHz}$ sampling rate) to localize seismic events (brown points),

- BRGM: piezometers to monitor the water level of the Rhaetian aquifer inside the sandstone $60 \mathrm{~m}$ above the "DdB" layer (blue points),

- INERIS: an automated tacheometer $( \pm 3 \mathrm{~mm}$ vertical accuracy) to monitor the displacement of a set of 17 reflectors across the cavity zone (yellow square and diamonds),

- BRGM: a set of 3 extensometers in a same drill hole to monitor deformation of the "DdB" layer, and extending from the surface down to different depths so as to be above $(113 \mathrm{~m})$, inside $(125 \mathrm{~m})$ and below $(129 \mathrm{~m})$ the dolomite layer (crossed circle),

- INERIS: a differential GPS for RTK measurements ( $\pm 5 \mathrm{~mm}$ vertical precision) with a stable base sensor and a mobile sensor at the middle of the anticipated collapse (green squares),

- BRGM (February 2009): 3 Güralp CMG40-TD broadband seismometer $(0.016$ to $50 \mathrm{~Hz}$ frequency band, $100 \mathrm{~Hz}$ sampling rate) in a 1-m-deep hole; two being associated with an accelerometer (green points),

- BRGM (February 2009): 1 continuously recording gravimeter (15 s sampling rate) (red square).

\section{Appendix B}

\section{Collapse mechanisms}

Based on a synthesis of all the monitoring results, including those presented in other publications (Contrucci et al., 2010; Daupley et al., 2010a, b; Jousset et al., 2010), the GISOS team can propose an overview of the collapse episodes (Fig. B1): 

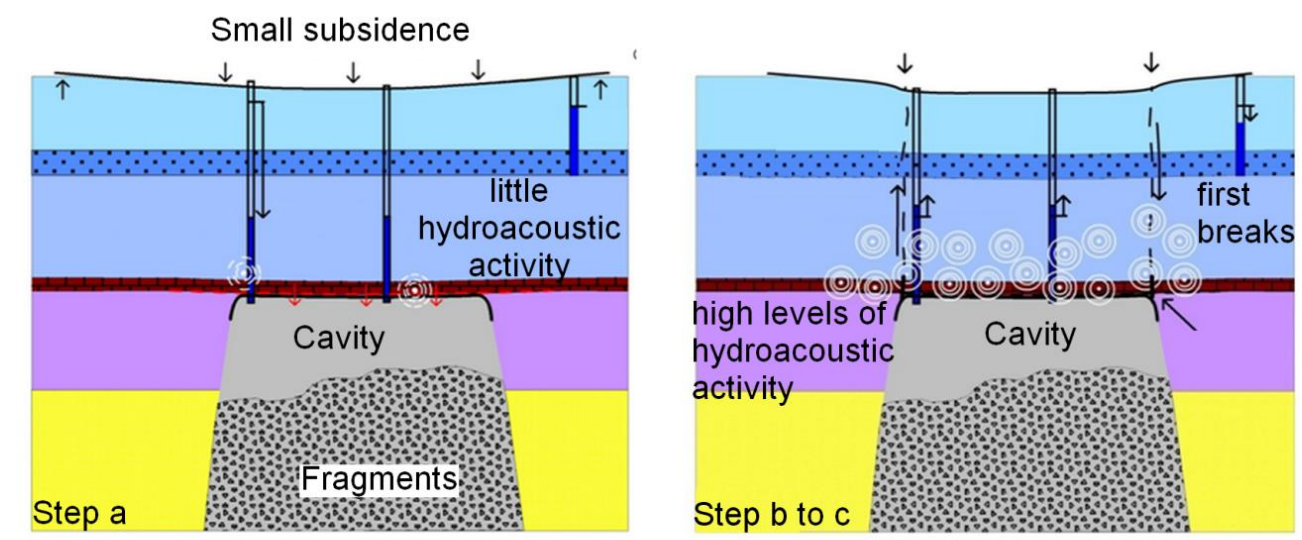

High subsidence
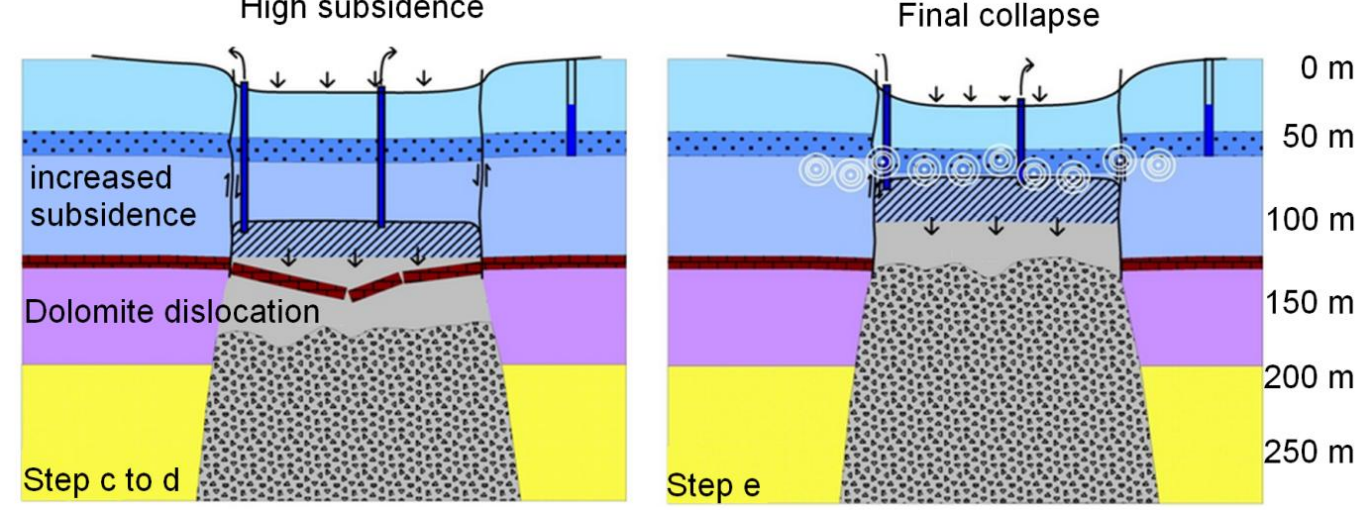

Adapted from Daupley, X. and al., Multiparameter monitoring of a salt cavern collapse (Cerville-Buissoncourt site, France), poster EGU2010-12404, 2010

Fig. B1. Collapse mechanism.

(a) From 10 February 2009 at 06:00 UT to 11 February 2009 at $\sim 18: 30 \mathrm{UT}$, pumping out the brine lowered the water level $60 \mathrm{~m}$ deeper. This led to increased stress inside the cavity roof and to a small subsidence at the surface ( $\sim 2$ to $4 \mathrm{~mm} \mathrm{~h}^{-1}$ ) revealed by both the extensometers and the topographic measurements (GPS, Tacheometer); little microseismic and hydroacoustic activity.

(b) At $\sim 18: 30$ UT the first ruptures were much localized above the cavity margin; they cut out a kind of cylinder ( $150 \mathrm{~m}$ in diameter, $120 \mathrm{~m}$ thick). This episode had an impact on all the measurements with, in particular, high levels of microseismic and hydroacoustic activity.

(c) The cylinder began to slip down as a single unit. Subsidence then accelerated and the cylinder pushed down on the brine whose level then rose continuously despite pumping. The cylinder slip induced a continuous high level of activity on the hydrophone inside it (Ch1, near the margin). This episode lasted until the morning of 12 February 2009, with the beginnings of the compe- tent "DdB" layer rupture taking place from $\sim 02: 00$ to $\sim 07: 00$ UT ("X" emissions).

(d) At $\sim 07: 00$ UT, the competent "DdB" layer lost all its strength and gradually dislocated (until 10:00 UT). This led to the damaging of several sensors (hydrophone, microseismic sensor, extensometers in order of depth) and an acceleration of the subsidence. The members of monitoring teams heard earth rumbling and all the inside sensors showed strong activity before being damaged.

(e) As of 10:00 UT the subsidence rate, which had gently reached $\sim 30 \mathrm{~mm} \mathrm{~h}^{-1}$, increased dramatically to $\sim 70 \mathrm{~mm} \mathrm{~h}^{-1}$ over slightly more than $12 \mathrm{~h}$; then at $\sim 21: 00$ UT, it began to exponentially accelerate, reaching more than $1400 \mathrm{~mm} \mathrm{~h}^{-1}$ (last GPS measurement was at 04:26 UT) just before the surface collapse which occurred at 04:45 UT on 13 February 2009. The subsidence speedup was recorded on both the microseismic and hydroacoustic (Ch2) activity measurements. 
Acknowledgements. The authors would like to thank the Lorraine Regional Authority for its backing of the GISOS teams, the mine operating team which provided the time and facilities that made the GISOS experiments possible, and all their GISOS colleagues for continuing support and discussion both in the field and afterwards.

Edited by: T. Maggipinto

Reviewed by: X. Lei and another anonymous referee

\section{References}

Aki, K. and Richards, P. G.: Quantitative seismology: theory and methods (Vol I and II), W.H. Freeman and Co: San fransisco, California, 1968.

Amitrano, D., Grasso, J. R., and Senfaute, G.: Seismic precursory patterns before a cliff collapse and critical-point phenomena, Geoph. Res. Lett., 32(8), L08314, doi:10.1029/2004GL022270, 2005.

Amitrano, D., Gaffet, S., Malet, J.-P., and Maquaire, O.: Understanding mudslides through micro-seismic monitoring: The Super-Sauze (South French Alps) case study, B. Soc. Geol. Fr., 178(2), 149-157, doi:10.2113/gssgfbull.178.2.149, 2007.

Amitrano, D., Arattano, M., Chiarle, M., Mortara, G., Occhiena, C., Pirulli, M. and Scavia, C. : Microseismic activity analysis for the study of the rupture mechanisms in unstable rock masses, Natural Hazard and Earth System Sciences, 10, 831-841, 2010.

Armstrong, B. H.: Acoustic emission prior to rockbursts and earthquakes, B. Seismol. Soc. Am., 59 (3), 1259-1279, 1969.

Baddari, K. and Frolov, A. D.: Modélisation de la structure fractale d'un milieu géophysique (Modeling of the fractal structure of a geophysical field), CR. Acad. Sci. II A, 1997.325, 925-930, 1997.

Bakhshaiesh, K.: Contribution to experimental study of mechanical and thermal damage in crystalline hard rocks, Doctoral thesis, Univ. Joseph Fourier, Grenoble, 2009.

Berbaoui, R., El Mahi, A., and El Guerjouma, R.: Analyse par émission acoustique de l'endommagement et de la rupture du béton polymère en fluage (Acoustic emission analysis of polymer concrete damage in creep), CR. JNC 16, Toulouse, 2009.

Carpinteri, A., Lacidogna, G., and Pugno, N.: Structural damage diagnosis and life-time assessment by acoustic emission monitoring, Eng. Fract. Mech., 74, 273-289, 2007.

Chichibu, A., Jo, K., Nakamura, M., Goto, T. and Kamata, M.: Acoustic emission characteristics of unstable slopes = Caractéristiques de l'émission acoustique des versants instables, Journal of Acoustic Emission, 8 (4), 107-112, 1989.

Contrucci, I., Cao, N. T., Klein, E., Daupley, X., and Bigarre P.: Real-time monitoring of a salt solution mining cavern: view from microseismic and levelling monitoring, oral communication, EGU2010-12256, 2010.

Dalmas, D., Benmedakhene, S., Richard, C., Laksimi, A., Béranger, G., and Grégoire, T.: Caractérisation par émission acoustique de l'adhérence et de l'endommagement d'un revêtement : cas d'un revêtement WC-Co sur acier, CR. Acad. Sci. C Chim., 4, 345350, 2001.

Daupley, X., Fabriol, R., Contrucci, I., Bernardie, S., Cao, N. T., Lebert, F., Cauvin, L., Jousset, Ph., Klein, E., and Bazargan, B.: Suivi expérimental multiparamètres de l'effondrement d'une cavité saline - Site de Cerville Buissoncourt (Multi parameter monitoring of a salt cavern collapse (Cerville-Buissoncourt site, France), oral communication, JNGG 2010-208., 2010a.

Daupley, X., Fabriol, R., Contrucci, I., Bernardie, S., Cao, N. T., Jousset, Ph., Klein, E., Lebert, F., and Bazargan, B.: Multiparameter monitoring of a salt cavern collapse (Cerville-Buissoncourt site, France), poster EGU2010-12404, 2010b.

de Ronde, A. A., Dobson, D. P., Meredith, P. G., and Boon, S. A.: Three-dimensional location and waveform analysis of microseismicity in multi-anvil experiments, Geophys. J. Int., 171, 12821294, 2007.

Ding, Y., Reuben, R. L., and Steel, J. A.: A new method for waveform analysis for estimating $\mathrm{AE}$ wave arrival times using wavelet decomposition, NDT\&E Int., 37, 279-290, 2004.

Dixon, N., Kavanagh, J., and Hill, R.: Monitoring landslide activity and hazard by acoustic emission, J. Geol. Soc. China, 39(4), 437-464, 1996.

Dixon, N., Hill, R., and Kavanagh, J.: Acoustic emission monitoring of slope instability: development of an active waveguide system, Geotechnical Engineering, 156(2), 83-95, 2003.

Fortin, J., Stanchits, S., Dresenh, G., and Gueguen, Y.: Acoustic Emissions Monitoring during Inelastic Deformation of Porous Sandstone: Comparison of Three Modes of Deformation, Pure Appl. Geophys., 166, 823-841, 2009.

Gaffet S., Guglielmi Y., Cappa F., Pambrun C., Monfret T., and Amitrano, D.: Use of the simultaneous seismic, GPS and meteorological monitoring for the characterization of a large unstable mountain slope in the southern French Alps, Geophys. J. International, 182(3), 1395-1410, 2010.

Geng, R. S.: Modern acoustic emission technique and its application in aviation industry, Ultrasonics, 44, e1025-e1029, 2006.

Hardy, H. R.: Acoustic emissions/Microseismic activity, A.A Balkema, 2003.

Helmstetter, A. and Garambois S.: Seismic monitoring of Séchilienne rockslide (French Alps): Analysis of seismic signals and their correlation with rainfalls, J. Geophys. Res., 115, 15 pp., doi:201010.1029/2009JF001532, 2010.

Jousset, Ph., Bazargan-Sabet, B., Lebert, F., Bernardie, S., and Gourry, J. C.: Geophysical observations at cavity collapse, oral communication EGU2010-4993, 2010.

Holcomb D. J.: 1993-General theory of the Kaiser effect, Int. J. RockMech, Min. Sci. \& Geomech. Abstr, 30, No. 7, 929-935, 1993.

Kaiser, J.: An Investigation into the Occurrence of Noises in Tensile Tests or a Study of Acoustic Phenomena in Tensile Tests, 1950 $\mathrm{Ph} . \mathrm{D}$. thesis, Tech. Hosch. Munchen, Munich, Germany.

Kolesnikov, Yu. I., Nemirovich-Danchenko, M. M., Goldin, S. V., and Seleznev, V. S.: Slope stability monitoring from microseismic field using polarization methodology, Nat. Hazards Earth Syst. Sci., 3, 515-521, doi:10.5194/nhess-3-515-2003, 2003.

Kui, Z., Xueyi, Z., Xiaojun, W., Jiefang, J., and Gengfeng, W.: Advances in Kaiser effect of rock acoustic emission based on wavelet analysis, PSU-UNS International Conference on Engineering and Environment - ICEE-2007, Phuket, May10-11, ICEE2007062, 204-207, 2007.

Kuksenko, V. S., Inzhevatkin, I. E., Manzhikov, B. Ts., Stanchits, S. A., Tomilin, N. G., and Frolov, D. I.: Physical and methodological principles of rock burst prediction, Translated from FizikoTekhnicheskie Problemy Razrabotki Poleznykh Iskopaemykh, 1, 9-22, 1987. 
Kuo, C. C.: Artificial recognition system for defective types of transformers by acoustic emission, Expert Syst. Appl., 36, 10304-10311, 2009.

Lai, X. P., Ren, F. H., Wu, Y. P., and Cai, M. F.: Comprehensive assessment on dynamic roof instability under fractured rock mass conditions in the excavation disturbed zone, Int. J. Min. Met. Mater., 16(1), 12, 2009.

Lavrov, A. V. and Shkuratnik, V. L.: Deformation- and FractureInduced Acoustic Emission in Rocks, Acoust. Phys., 51 (Suppl. 1), S2-S11, 2005.

Lei, X. L.: How do asperities fracture? An experimental study of unbroken asperities, Earth Planet. Sci. Lett., 213, 347-359, 2003.

Lei, X. L.: Typical phases of pre failure damage in granitic rocks under differential compression, Geol. Soc Spec. Publ., 261, 1129, 2006.

Lei, X. L. and Satoh T.:, Indicators of critical point behavior prior to rock failure inferred from pre-failure damage, Tectonophysics, 431, 97-111, 2007

Lei, X. L., Nishizawa, O., Kusunose, K., Cho, A., Satoh, T., and Nishizawa, O.: Compressive failure of mudstone samples containing quartz veins using rapid $\mathrm{AE}$ monitoring: the role of asperities, Tectonophysics, 328, 329-340, 2000.

Lei, X. L., Kusunose, K., Satoh, T., and Nishzawa, O.: The hierarchical rupture process of a fault: an experimental study, Phys. Earth Planet. In., 137, 212-228, 2003.

Linder, R., Reymond, M. C., Vecoven, J., and Cherfaoui, M.: Emission acoustique appliquée à l'étude des matériaux de chaussée, Premier congrès français d'acoustique, Colloque de physique C2-77, Supplément au no. 2, Tome 51, 1990.

Lockner, D. A.: The role of acoustic emission in the study of rock fracture, Int. J. Rock Mech. Min., 30(7), 883-899, 1993.

Majeed, M. A. and Murthy, C. R. L.: A model with nonzero rise time for AE signals, Sadhana, 25(5), 465-474, 2001.

Michihiro, K., Hata, K., Fujiwara, T., and Yoshioka, H.: Prediction of failure in rock masses by acoustic emission, Mater. Sci. Res. Int., 3(2), 106-110, 1997.

Moura, A., Lei, X. L., and Nishisawa, O.: Prediction scheme for the catastrophic failure of highly loaded brittle materials or rocks, J. Mech. Phys. Solids, 53, 2435-2455, 2005.

Moura, A., Lei, X. L., and Nishisawa, O.: Self-similarity in rock cracking and related complex critical exponents, J. Mech. Phys. Solids, 54, 2544-2553, 2006.

Obert, L.: Use of subaudible noises for prediction of rock burst, Report of Investigation 3555, US Bureau of Mines 4, 1941.

Obert, L.: The microseismic method: discovery and early history, First Conf. on Acoustic Emission/Microseismic Activity in Geologic Structures and Materials, 11-12, Trans Tech Publications, 1977.

Prikryl, R., Lokajicek, T., Li, C., and Rudajerv, V.: Acoustic emission characteristics and failure of uniaxially stressed granitic rocks: the effect of rock fabric, Rock Mech. Rock Eng., 36(4), 255-270, 2003.
Rao, M. V. M. S. and Prasanna Lakshmi, K. J.: Analysis of b-value and improved b-value of acoustic emissions accompanying rock fracture, Curr. Sci. India, 89(9), 1577-1582, 2005.

Reymond, M. C.: Etude de la fissuration des éprouvettes sous contrainte en laboratoire et des massifs rocheux en carrière par une méthode d'émission acoustique, Rock Mech., 7, 1-16, 1975.

Richeton, T.: Dynamique et complexité de la déformation plastique : étude par émission acoustique, Doctoral thesis, Science et Génie des Matériaux (INP Grenoble, Laboratoire de Glaciologie et Géophysique de l'Environnement), 2006.

Sagaidak, A. I. and Elizarov, S. V.: Acoustic emission parameters correlated with fracture and deformation processes of concrete members, Constr. Build. Mater., 21, 477-482, 2007.

Senfaute G., Chambon, C. Bigarre, P., Guise, Y., and Josien, J.P.: Spatial Distribution of Mining Tremors and the Relationship to Rockburst Hazard, Pure Appl. Geophys., 150, 451-459, 1997.

Senfaute, G., Amitrano, D., Lenhard, F., and Morel, J.: Etude en laboratoire par méthodes acoustiques de l'endommagement des roches de craie et corrélation avec des résultats in situ, Rev. Fr. Géotechnique.,110, 9-17, 2005.

Senfaute, G., Duperret, A., and Lawrence, J. A.: Micro-seismic precursory cracks prior to rock-fall on coastal chalk cliffs: a case study at Mesnil-Val, Normandie, NW France, Nat. Hazards Earth Syst. Sci., 9, 1625-1641, doi:10.5194/nhess-9-1625-2009, 2009.

Shaira, M.: Caractérisation non destructive de la transformation martensitique de l'acier 304L induite par déformation cyclique (Chapitre 3: Evaluation non destructive de l'endommagement d'un matériau dispersif (le béton) par émission acoustique et par ultrasons), Doctoral thesis, Institut National des Sciences Appliquées de Lyon, [08/01/2007], 2006.

Smith, R., Sammonds, P. R., and Kilburn, C. R. J.: Fracturing of volcanic systems: Experimental insights into pre-eruptive conditions, Earth Planet. Sci. Lett. 280, 211-219, 2009.

Srinivasan, C., Arora, S. K., and Benady, S.: Precursory monitoring of impending rockbursts in Kolar gold mines from microseismic emissions at deeper levels, Int. J. Rock Mech. Min., 36, 941-948, 1999.

To, A. C. and Glasera, S. D.: Full waveform inversion of a 3-D source inside an artificial rock, J. Sound Vib., 285, 835-857, 2005.

Toubal, L., Lorrain, B., Karama, M., and Marlot, D.: Suivi par émission acoustique et caméra infra rouge d'un essai de fatigue, Contrôle-essais-mesures supplément au No. October 2006, 26287, 2006.

Vilhelm, J., Rudajev, V., Lokajıcek, T., and Zivor, R.: Application of autocorrelation analysis for interpreting acoustic emission in rock, Int. J. Rock Mech. Min., 45, 1068-1081, 2008.

Willenberg, H., Evans, K. F., Eberhardt, E., Loew, S., Spillmann, T., and Maurer, H.: Geological, geophysical and geotechnical investigations into the internal structure and kinematics of an unstable sliding mass in crystalline rock, Proceedings of the 9th International Symposium of Landslides, Rio de Janeiro, Brazil, 489-494, 2004 